\title{
Negative affect, pain and disability in osteoarthritis patients: the mediating role of muscle weakness
}

\author{
Joost Dekker, ${ }^{1 *}$ Paolo Tola, ${ }^{2}$ Geert Aufdemkampe ${ }^{2}$ and Marcus Winckers ${ }^{1}$ \\ 'Netherlands Institute of Primary Health Care, P.O. Box 1568, 3500 BN Utrecht, The Netherlands and \\ ${ }^{2}$ Central Netherlands Polytechnic, Department for Physical Therapy, Utrecht, The Netherlands
}

(Received 25 March 1992)

\begin{abstract}
Summary-Negative affect has been shown to be associated with high levels of pain and disability in osteoarthritis (OA) patients. As an explanation of this association, it was hypothesized that muscle weakness is a mediating factor between negative affect, pain and disability. Accordingly, negative affect enhances the patient's tendency to avoid pain-related activities; a low activity level induces muscle weakness, instability of joints and thus pain and disability. This theory leads to the prediction that the association between negative affect, pain and disability is most pronounced in patients with weak muscles. The prediction was tested in a study on patients with OA of the hip and/or knee. Regarding disability (but not pain), the prediction was confirmed. This study indicates that muscle weakness is a mediating factor between negative affect and disability in OA-patients.
\end{abstract}

\section{INTRODUCTION}

It has been shown that negative affect is associated with higher levels of pain and disability in osteoarthritis (OA) patients (for a review see Dekker, Boot, Van der Woude \& Bijlsma, 1992a). For example, in a study controlling for the level of joint degeneration, anxious patients were found to experience higher levels of pain (Summers, Haley, Reveille \& Alarcan, 1988). Similarly, patients who perceived themselves as in control of pain and who tended not to catastrophize, showed higher walking speed and less pain (Keefe, Caldwell, Queen, Gil, Martinez, Crisson, Ogden \& Nunley, 1987a, b). The mechanisms which cause these associations are not clear, however. Several mechanisms have been hypothesized in the literature, but empirical evidence in support of these mechanisms is largely absent (Dekker et al., 1992a).

One mechanism which might explain these associations is concerned with the avoidance of pain-related activity (Turk and Flor, 1984; Dolce and Raczynski, 1985; Keefe and Gil, 1986; Philips, 1987). This mechanism is described in Fig. 1. Accordingly, OA patients tend to avoid activity, because activity induces pain. The avoidance of activity is a two-edged sword, however. A low activity level enhances muscle weakness and instability of joints. Instability of joints causes strain in innervated tissues and thus pain. Also, instability causes limitations in activities and tasks (disabilities). It has been hypothesized that negative affect enhances this vicious circle. Negative affect - defined as 'a broad range of aversive mood states, including anger, distrust, scorn, guilt, fearfulness, and depression' (Watson and Pennebaker, 1989) is thought to strengthen the tendency to avoid activity (Dekker $e t$ al, 1992a). This mechanism could explain the association of negative affect, pain and disability in $O A$ patients.

From this theoretical model, the hypothesis can be derived that the association of negative affect, pain and disability will be particularly marked in patients with weak muscles. In patients with normal muscles, there is no reason to expect an association, because a necessary mediating factor-muscle weakness-is lacking. Thus, it was hypothesized that the association of negative affect, pain and disability will be stronger in patients with weak muscles than in patients with normal muscles. The present study was designed to test this hypothesis in patients with $\mathrm{OA}$ of the hip and/or knee.

\section{Patients}

\section{METHOD}

Patients with a medical diagnosis of $O A$ of the knee or hip, who had been referred by a physician to a physical therapist, were eligible for inclusion in this study. Six physical therapy practices participated in the selection of patients. Patients were excluded if they did not consent or if they were not able to walk around for approximately $10 \mathrm{~min}$. Patients stated their informed consent before entering the study. Fifty-eight patients were included, 48 women and 10 men. Their mean age was $70 \mathrm{yr}(\mathrm{SD} 13.6 \mathrm{yr}$ ). Thirty two patients had a diagnosis of OA of the knee, 12 OA of the hip and $14 \mathrm{OA}$ of both the knee and the hip. Because pain and disability was not significantly different in patients with OA of the hip, OA of the knee, or both, no further distinction was made between these diagnostic categories.

\section{Assessment}

Pain. An 11-point numerical rating scale was used to assess the experience of pain (cf., Downie, Leatham, Rhind, Wright, Branco \& Anderson, 1978). Patients rated their present level of pain on a scale ranging from 0 (no pain) to 10 (worst pain that I can imaginc).

Disability. Patients' performance on a series of standardized tasks was assessed using an adaptation and elaboration of the method described by Keefe et al. (1987b). These standardized tasks included standing, sitting down on a chair, reclining on a bed, walking up and down, walking with great strides, picking up an object from the floor (stooping), and walking a $5 \mathrm{~m}$ course. The following aspects of the patients' performance were assessed: (a) the time it took the patient to walk $5 \mathrm{~m}$;

*Author for correspondence. 


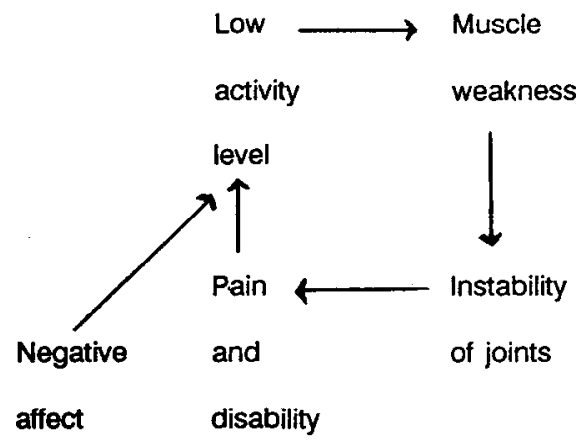

Fig. 1. Proposed causes of pain and disability in OA patients.

(b) the time it took the patient to sit down (two trials); (c) the time it took the patient to recline on the bed (two trials); (d) guarding: abnormally slow, interrupted or irregular movement while performing a cyclical movement (walking and striding); (e) rigidity: excessive stiffness of an affected joint, while performing a noncyclical movement (sitting down, reclining and stooping); (f) unloading of a joint: an affected limb does make contact with the floor, but it hardly bears weight (shifting weight to the other side of the body, using a stick or seeking support on equipment). The details of this assessment have been described clsewherc (Dckker, Tola \& Aufdcmkampe, 1990; Dekker, Tola, Aufdemkampe \& Winckers, 1992b).

Negative affect. The Dutch language version of the Profile of Mood States (POMS; Wald, 1984) was used. The following negative mood states were assessed: tension (anxiety), depression, fatigue and anger. In addition, 'catastrophizing' was assessed using a subscale from a Dutch coping questionnaire (Kraaimaat and Huiskes, 1989).

Muscle strength. The strength of several muscle groups was tested manually and rated on the scale of Kendall, Kendall and Wadsworth (1971). This 6-point scale was reduced to a dichotomy: 'normal muscles' representing the higher Kendall grades (80-100\%); 'weak muscles' representing the lower Kendall grades. The muscle tests were performed statically, with the joint in a half-way position. Manual force (or gravity) was applied for $10 \mathrm{sec}$. Muscle testing was done by a physical therapist. Manual muscle testing has been shown to be reliable, provided that the data are reduced to broad categories (normal vs weak muscles; Lamb, 1985; van Triet, Dekker, Kerssens \& Curfs, 1990). Regarding the knee, the strength of muscles causing knee extension was assessed (left and right). These two scores (left and right) were combined into a single, overall score: if both muscles groups were normal, the overall knee muscle strength was scored as normal; if one or both muscle groups was weak, the overall knee muscle strength was scored as weak. Regarding the hip, the strength was assessed of muscles causing hip flexion, extension, internal rotation, external rotation, abduction and adduction (left and right). These 12 scores were combined into a single overall score: if all muscle groups were normal, the overall hip muscle strength was scored as normal; if one or more groups were weak, the overall hip muscle strength was scored as weak. Evidence on the validity of these overall scores is presented in the next sections of the present paper.

\section{Procedure}

After a brief introduction, the patient rated his or her current level of pain (first trial) and completed the questionnaires concerning negative affect. Subsequently, the muscle tests and the disability measurements were performed. The patient once again rated his or her current level of pain (second trial). Finally, the patient was debriefed.

\section{Statistical analysis}

Originally, the intention was to use MANOVAs to test the main and interaction effects of negative affect and muscle strength, the dependent variables being pain and disability. However, because of a substantial inhomogeneity of variance, this approach was precluded. Instead, three separate tests were used. (1) The effect of muscle strength on the dependent variables was tested with $t$-tests with separate variance estimates. (2) Pearson correlations were computed to test the

Table 1. Pain and disability in patients with weak and normal muscles: mean scores (and standard deviations)

\begin{tabular}{|c|c|c|c|c|c|c|}
\hline & \multicolumn{3}{|c|}{ Knee muscles } & \multicolumn{3}{|c|}{ Hip muscles } \\
\hline \multicolumn{7}{|l|}{ Pain } \\
\hline 1st trial & $3.4(1.6)$ & $3.2(2.2)$ & N.S. & $3.7(2.2)$ & $2.3(1.7)$ & *** \\
\hline 2nd trial & $4.4(2.4)$ & $3.2(2.5)$ & N.S. & $3.7(2.6)$ & $2.6(2.2)$ & $*$ \\
\hline \multicolumn{7}{|l|}{ Disability } \\
\hline lst trial & $6.6(2.8)$ & $4.4(1.4)$ & $*$ & $5.2(2.0)$ & $3.8(0.8)$ & $* * *$ \\
\hline 2nd trial & $4.8(1.0)$ & $4.2(1.2)$ & N.S. & $4.6(1.2)$ & $3.7(1.1)$ & $* *$ \\
\hline \multicolumn{7}{|l|}{ Recline time } \\
\hline lst trial & $13.3(6.6)$ & $7.1(2.7)$ & $*$ & $9.0(4.2)$ & $5.8(1.0)$ & $* * *$ \\
\hline 2nd trial & $12.9(4.4)$ & $7.4(3.5)$ & $* *$ & $9.3(4.3)$ & $5.9(2.2)$ & $* * *$ \\
\hline Guarding & $7.1(1.9)$ & $3.7(3.3)$ & $* * *$ & $5.3(3.0)$ & $2.0(3.0)$ & $* m *$ \\
\hline
\end{tabular}

†Logarithmic transformation.

$\pm t$-test (separate variance estimate).

$* P<0.05 ; * * P<0.01 ;{ }^{* * *} P<0.001$ 
Table 2. Correlation between negative affect, pain and disability

\begin{tabular}{llrrrr}
\hline & Fatigue & Depression & Anger & Tension & Catastrophizing \\
\hline Pain & & & & & \\
$\quad$ 1st trial & $0.37^{* * *}$ & 0.14 & -0.10 & $0.27^{*}$ & -0.04 \\
$\quad \begin{array}{l}\text { 2nd trial } \\
\text { Disability }\end{array}$ & $0.35^{* * *}$ & 0.08 & 0.01 & 0.20 & 0.08 \\
$\quad$ Walking time & & & & & \\
Sit time & $0.22^{*}$ & 0.13 & 0.04 & 0.20 & 0.10 \\
$\quad$ 1st trial & & & & & \\
2nd trial & 0.12 & -0.04 & 0.10 & 0.08 & 0.15 \\
Recline time & 0.15 & 0.04 & 0.10 & 0.07 & 0.12 \\
$\quad$ 1st trial & & & & & \\
2nd trial & $0.24^{*}$ & 0.08 & 0.17 & 0.10 & $0.25^{*}$ \\
Guarding & $0.27^{*}$ & 0.07 & 0.16 & 0.17 & 0.19 \\
Rigidity & 0.09 & 0.04 & -0.13 & 0.10 & 0.12 \\
Unloading joint $\dagger$ & 0.05 & -0.07 & -0.02 & -0.11 & 0.18 \\
\hline & $0.32^{* *}$ & 0.07 & 0.15 & 0.17 & 0.07 \\
\hline
\end{tabular}

+ Logarithmic transformation.

${ }^{*} P<0.05 ;{ }^{* *} P<0.01 ;{ }^{* *} P<0.005$ (one tail).

association of negative affect with the dependent variables. (3) The main hypothesis was tested by calculating the same correlations, separately for patients with weak muscles and patients with normal muscles. Corresponding correlations were compared and the number of times the correlations were higher in the weak muscle group than in the strong muscle group was counted; similarly, the number of times these correlations were equal or lower was counted. The binomial test was used to test whether these numbers were significantly different.

Muscle strength, pain and disability

\section{RESULTS}

The mean levels and standard deviations of pain and disability in patients with weak and normal muscles are displayed in Table 1. Pain and disability was significantly higher in patients with weak hip muscles. Similarly, disability (but not pain) was significantly higher in patients with weak knee muscles. These results are compatible with the existence of a vicious circle as described in Fig. 1: avoidance of pain, muscle weakness, instability of joints and thus more pain and disability.

\section{Negative affect, pain and disability}

The Pearson correlations between negative affect, pain and disability are displayed in Table 2. Although some correlations were significant, most of them were not. Thus, this study failed to replicate the association of negative affect, pain and disability reported by others.

\section{Muscle strength, negative affect, pain and disability}

The Pearson correlations between negative affect, pain and disability were calculated, separately for patients with weak muscles or normal muscles. The corresponding correlations were compared: the results are shown in Table 3. As expected, correlations between negative affect and disability were higher in patients with weak muscles. This applied to both muscles of the hip and muscles of the knee. The correlations between negative affect and pain did not show the expected pattern, however: no significant difference was observed with the muscles of the hip and a significant but reverse difference was observed with the muscles of the knee. Thus, there is mixed support for the main hypothesis of this study.

\section{DISCUSSION}

Negative affect is hypothesized to enhance a vicious circle consisting of avoidance of pain related activities, muscle weakness, instability of joints, pain and disability (see Fig. 1). The main hypothesis derived from this model-that the association of negative affect, pain and disability will be higher in patients with weak muscles than patients with strong

Table 3. Comparison of correlations between negative affect, pain and disability in patients with weak and normal muscles

\begin{tabular}{|c|c|c|}
\hline & $N$ & Significance $\dagger$ \\
\hline \multicolumn{3}{|l|}{$\begin{array}{l}\text { Correlations between negative affect and pain } \\
\text { Knee }\end{array}$} \\
\hline 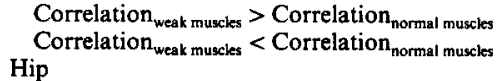 & $\begin{array}{r}0 \\
10\end{array}$ & $* *$ \\
\hline $\begin{array}{l}\text { Correlation }_{\text {weak muscles }}>\text { Correlation }_{\text {normal muscles }} \\
\text { Correlation }_{\text {weak muscles }}<\text { Correlation normal muscles }_{\text {non }}\end{array}$ & $\begin{array}{l}3 \\
7\end{array}$ & N.S. \\
\hline \multicolumn{3}{|l|}{$\begin{array}{l}\text { Correlations between negative affect and disability } \\
\text { Knee }\end{array}$} \\
\hline $\begin{array}{l}\text { Correlation }_{\text {weak muscles }}>\text { Correlation }_{\text {normal muscles }} \\
\text { Correlation } \\
\text { Hip }\end{array}$ & $\begin{array}{r}32 \\
8\end{array}$ & $*$ \\
\hline $\begin{array}{l}\text { Correlation } \\
\text { Correlak muscles }>\text { Correlation }_{\text {normal muscles }} \\
\text { weak muscies }\end{array}$ & $\begin{array}{l}29 \\
11\end{array}$ & * \\
\hline
\end{tabular}


muscles-was partially supported. With regard to disability, the hypothesis was confirmed: correlations were higher both in patients with weak hip muscles and in patients with weak knee muscles. With regard to pain, the hypothesis was not confirmed (hip) and even contradicted (knee). One possible explanation of this contradictory finding is the very low number of $S \mathrm{~s}$ with weak knee muscles $(n=7)$ : with such a low number, deviant results due to chance might be expected. Therefore, a replication of the present study is clearly required. The findings with regard to disability are sufficiently encouraging to warrant a replication study: the present study seems to be the first empirical evidence in support of the hypothesis that muscle weakness is a mediating factor between negative affect and disability in OA patients.

Although some were significant, most correlations between negative affect, pain and disability were not. Apparently, this study failed to replicate the results of Summers et al. (1988), Keefe et al. (1987) and others (see Dekker et al., 1992a). Differences between patient samples might be responsible for this. The present sample came from primary health care (instead of pain clinics): possibly these patients are in a better physical condition than patients from pain clinics. According to the main hypothesis of the present study, low correlations would be expected in such patients. The main hypothesis predicts that high correlations will be observed in patients with a poor physical condition (weak muscles) only.

It should be noted that, although most correlations between negative affect and disability were not significant, these correlations were found to be higher in patients with weak muscles. At first sight, this might seem somewhat contradictory. However, this is not true and it might be helpful to conceptualize these findings in terms of analysis of variance: although the main effect of negative affect on disability was not signiticant, there was a significant interaction effect of negative affect and muscle strength on disability.

Patients with weak muscles showed higher levels of pain and disability, which confirms the observations of Lankhorst, van de Stadt \& van der Korst (1985) (see also Dekker el al., 1992a). Although a prospective study would be more convincing, these results support the idea of a vicious circle described in Fig. 1. Additionally, these results show that the muscle tests (and the way these data were reduced) are valid: using these tests, the expected differences in pain and disability of patients with weak vs normal muscles were observed.

Finally, a clinical implication of the present study can be pointed out. Psychologists and physical therapists should closely cooperate in the treatment of disability in OA patients. Because disability is determined by negative affect and muscle weakness -jointly and in interaction specialists in the treatment of these factors (i.e. psychologists and physical therapists) should cooperate in the treatment of disability in OA patients.

\section{REFERENCES}

Dekker, J., Tola, P., Aufdemkampe, G. \& Winckers, M. (1992b). Categories of pain behavior: relationship to tasks and mutual association. Submitted for publication.

Dekker, J., Boot, B., van der Woude, L. H. V. \& Bijlsma, J. W. J. (1992a). Pain and disability in osteoarthritis patients: a review of biobehavioral mechanism. Journal of Behavioural Medicine, 15, 189-214.

Dekker, J., Tola, P. \& Aufdemkampe, G. (1990). Pijngedrag: de betrouwbaarheid van een meet-instrument bij gon- en coxartrose. Nederlands Tÿdschrift voor Fysiotherapie, 100, 106-110.

Dolce, J. J. \& Raczynski, J. M. (1985). Neuromuscular activity and electromyography in painful backs: psychological and biomechanical models in assessment and treatment. Psychological Bulletin, 97, 502-520.

Downie, W. W., Leatham, P. A., Rhind, V. M., Wright, V., Branco, J. A. \& Anderson, J. A. (1978). Studies with pain rating scales. Annals of the Rheumatic Diseases, 37, 378-381.

Keefe F. J. \& Gil K. M. (1986). Behavioral concepts in the analysis of chronic pain syndromes. Journal of Consulting and Clinical Psychology 54, 776-783.

Keefe, F. J., Caldwell, D. S., Queen, K. T., Gil, K. M., Martinez, S., Crisson, J. E., Ogden, W. \& Nunley, J. (1987a). Pain coping strategies in osteoarthritis patients. Journal of Consulting and Clinical Psychology, 55, 208-212.

Keefe, F. J., Caldwell, D. S., Queen, K. T., Gil, K. M., Martinez, S., Crisson, J. E., Ogden, W. \& Nunley, J. (1987b). Osteoarthritic knee pain: a behavioral analysis. Pain, 28, 309-321.

Kendall, H., Kendall, F. \& Wadsworth, G. (1971). Muscle testing and function (2nd edn); Baltimore MD: Williams and Wilkins.

Kraaimaat, F. W. \& Huiskes, C. J. A. E. (1989). Stress en pijn bij patiënten met rheumatoïde arthritis. Gedragstherapie, 22, 267-277.

Lamb, R. L. (1985). Manual muscle testing. In Rothstein, J. M. (Ed.), Measurement in physical therapy. New York: Churchill Livingstone.

Lankhorst, G. J., van de Stadt, R. J. \& van der Korst, J. K. (1985). The relationships of functional capacity, pain and isometric and isokinetic torque in osteoarthritis of the knee. Scandinavian Journal of Rehabilitation Medicine, 17, $167-172$.

Philips, H. C. (1987). Avoidance behaviour and its role in sustaining chronic pain. Behaviour Research and Therapy, 25, 273-279.

Summers, M. N., Haley, W. E., Reveille, J. D. \& Alarcan, G. S. (1988). Radiographic assessment and psychologic variables as predictors of pain and functional impairment in osteoarthritis of the knee or hip. Arthritis and Rheumatism, 31, 204-209.

van Triet, E. F., Dekker, J., Kerssens, J. J. \& Curfs, E. Chr. (1990). Reliability of the assessment of impairments and disabilities in survey research in the field of physical therapy. International Disability Studies, 12, 61-65.

Turk, D. C. \& Flor, H. (1984). Etiological theories and treatments for chronic back pain II. Psychological models and interventions. Pain, 19, 209-233.

Wald, F. (1984). De verkorte POMS. Amsterdam: Universiteit van Amsterdam.

Watson, D. \& Pennebaker, J. W. (1989). Health complaints, stress and distress: cxploring the central role of negative affectivity. Psychological Review, 96, 234-254. 